\title{
UCSF
}

UC San Francisco Previously Published Works

Title

'You should build yourself up as a whole product': Transgender female identity in Lima, Peru.

Permalink

https://escholarship.org/uc/item/12760714

Journal

Global public health, 11(7-8)

ISSN

1744-1692

Authors

Pollock, Lealah

Silva-Santisteban, Alfonso

Sevelius, Jae

et al.

Publication Date

2016-08-01

DOI

10.1080/17441692.2016.1167932

Peer reviewed 


\section{Global Public Health}

\section{'You should build yourself up as a whole product': Transgender female identity in Lima, Peru}

\section{Lealah Pollock, Alfonso Silva-Santisteban, Jae Sevelius \& Ximena Salazar}

To cite this article: Lealah Pollock, Alfonso Silva-Santisteban, Jae Sevelius \& Ximena Salazar (2016): 'You should build yourself up as a whole product': Transgender female identity in Lima, Peru, Global Public Health, DOI: 10.1080/17441692.2016.1167932

To link to this article: http://dx.doi.org/10.1080/17441692.2016.1167932

\section{曲 Published online: 15 Apr 2016.}

\section{Submit your article to this journal $\square$}

Џ Article views: 11

Q View related articles $\longleftarrow$

View Crossmark data ¿ 


\title{
'You should build yourself up as a whole product': Transgender female identity in Lima, Peru
}

\author{
Lealah Pollock ${ }^{a}$, Alfonso Silva-Santisteban ${ }^{b}$, Jae Sevelius ${ }^{c}$ and Ximena Salazar ${ }^{b}$ \\ ${ }^{a}$ Department of Family and Community Medicine, University of California, San Francisco, San Francisco, CA,

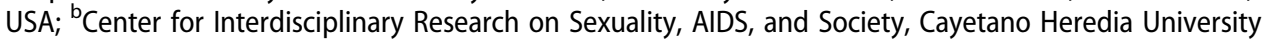 \\ (Centro de Investigación Interdisciplinaria en Salud, Sida, y Sociedad de la Universidad Peruana Cayetano \\ Heredia), Lima, Peru; 'Department of Medicine, Center for AIDS Prevention Studies, Center of Excellence for \\ Transgender Health, University of California, San Francisco, San Francisco, CA, USA
}

\begin{abstract}
Transgender women in Lima, Peru have, until recently, been grouped together with gay and bisexual men in the category MSM, or men who have sex with men, with little consideration of their unique situation and needs. Transgender women, self-identified in Peru as travesti, are a socially vulnerable population with many unmet health needs, including an HIV prevalence of $30 \%$. Understanding specific transgender identities and their contexts will contribute to the improvement and development of HIV prevention programs. Through qualitative open-ended interviews with trans-identified women in Lima, Peru, this study found that the non-normative travesti identity is constructed within a conservative homophobic and heteronormative social context. Participants strive towards appearances and relationships perceived as feminine, seeking out silicone injections and abusive men as social markers of this femininity. Sex work is the primary economic activity available and travestis are often alienated from their families and communities. Work is needed to increase selfesteem and decrease violence, stigma, and discrimination. There is a need for multilevel HIV prevention campaigns prioritising travesti in Lima, utilising a human rights framework.
\end{abstract}

\section{ARTICLE HISTORY}

Received 24 February 2015

Accepted 1 March 2016

\section{KEYWORDS}

Transgender persons; gender identity; HIV; Latin America

\section{Introduction}

Worldwide, individuals who are born male and have a feminine gender identity are disproportionately affected by HIV infection (Baral et al., 2013). In Peru, a country with an overall adult HIV prevalence around $0.4 \%$, the HIV prevalence among transgender women in Lima is 30\% (Silva Santisteban et al., 2012). Qualitative research with transgender women has suggested that gender identity itself may be an important factor in the context of HIV risk, primarily by increasing engagement in sexually risky behaviours (Bockting, Robinson, \& Rosser, 1998; Melendez \& Pinto, 2007; Operario, Nemoto, Iwamoto, \& Moore, 2011; Reisner et al., 2009; Salazar et al., 2006; Sevelius, 2013; Villayzán, personal communication, (L. Pollock), 2010). Fostering understanding of culturally and geographically distinct transgender identities will help clarify the context of transgender HIV risk. 


\section{Travesti identity}

In Latin America, anthropological and sociological study of transgender populations has primarily focused on individuals identified as travesti, biological males who manifest a feminine gender identity and adopt traits socially designated female (Barreda, 1993; Kulick, 1998; Vieria Garcia, 2008). Until recently, all public health research in Peru that included travestis lumped them together with gay and bisexual men in the category MSM, or men who have sex with men (Cáceres et al., 2008; Salazar \& Villayzán, 2009; Salazar, Villayzán, Silva Santisteban, \& Cáceres, 2010). As more is known about the HIV epidemic in Peru and its affected subgroups, an understanding has emerged of a community of female-dressing and female-identified travestis or mujeres trans (trans women), as distinct from gay or bisexual men (Salazar et al., 2010; Salazar \& Villayzán, 2009). However, defining this population has proven problematic, because they are often inadequately captured by epidemiological terminology (Cáceres, 1996).

Travesti identity in Lima exists within a context of machismo and gender-based violence. According to a government survey in 2014, 72.4\% of women have experienced some sort of violence from a spouse or partner (Instituto Nacional de Estadística e Informática, 2014). Seventy per cent reported experiencing verbal or psychological abuse, $32 \%$ reported physical abuse, and $8 \%$ reported sexual abuse. Among the women who had experienced verbal or psychological abuse, $65 \%$ had a partner who had exerted some sort of control, primarily in the forms of jealousy and insistence on knowing where she was at all times. These subtle forms of violence and control are so common as to be considered 'normal' by many Peruvian women.

While much is known about the Peruvian context of discrimination and marginalisation faced by travestis, limited qualitative studies have been conducted focusing on travesti identity itself in a Peruvian context. Qualitative research in Peru indicates that travestis are faced with a daily situation of violence, stigma, discrimination, and low self-esteem; suffer from a lack of education, employment, and housing opportunities; are frequent victims of interpersonal and police violence; and have high rates of substance use (Salazar, 2005; Salazar et al., 2010). The primary economic options available are hairdressing and sex work, which further increases their social vulnerability (Silva Santisteban et al., 2012). Due primarily to a lack of other job opportunities, many travestis participate in sex work at some point in their lives (Salazar et al., 2010).

Travestis in Peru have begun to fight for rights and recognition. To build interventions, mobilise an activist movement, and conduct further investigations, it is important to understand what it means to be travesti. This study aims to explore contruction(s) of gender identity and the individual and social contexts of travestis in Lima, Peru, to clarify the social context of vulnerability, including vulnerability to HIV, in this underserved, at-risk population. The analysis pays special attention to the way in which travesti identity is constructed within the social constraints of normative ideas of masculinity, femininity, and heterosexuality.

\section{Methods}

Fifteen in-depth open-ended interviews were completed. Investigators worked with field workers familiar with the population to identify and recruit participants. Field workers 
were asked to locate participants who identify as trans or travesti, and/or who have a feminine identity and use full-time female dress. Interviews were conducted in five unique neighbourhoods in the Province of Lima. These neighbourhoods ranged from innercity' to more suburban, and were all low socio-economic class. These neighbourhoods were chosen because they were part of a larger ongoing research project involving community centre building, so the researchers had a pre-existing relationship with some community members. In two of the neighbourhoods, the field worker introduced one of the investigators to an individual identified as a travesti leader within that neighbourhood. This individual, in turn, identified and helped to recruit other individuals who would be eligible for and interested in the study. In the three other neighbourhoods, the field workers directly identified potential participants, who were approached for recruitment jointly with one of the investigators. Individuals were eligible for participation if they were born male and present as female at least part of the time, were 18 years of age or older, and were able to understand and give informed consent.

The interviews consisted of a series of open-ended and interactive questions, exploring themes related to gender identity, self-esteem, drug and alcohol use, relationships, condom use, sex work, and body modification. Participants were paid 10 Peruvian Soles (approximately \$3.50) for their participation and were provided with snacks. The interviews were conducted by a single cis-female American bilingual researcher, lasted between one and two hours, and were recorded and transcribed in Spanish, then translated to English. The interviews were translated by a native Peruvian. The interviewer spot-checked the translations, giving suggestions as the translations were being completed, and doublechecked the transparency (i.e. the quality of sounding like a native speaker) and fidelity of the final quotes.

After the initial analysis was complete, two focus groups were held with individuals who had not previously been interviewed for validation of major results. Participants in focus groups had to be at least 18 years of age and identify as gay, homosexual, mujer trans, transformista, or travesti. One focus group consisted of four participants and another of eight. These focus groups were held in two neighbourhoods different from the initial five, although similar in socio-economic terms. Field notes were taken at both focus groups. The authors chose to start with in-depth interviews to gain insight into individual perspectives on sensitive subject matter and followed up with focus groups to validate the generalisability of our findings.

Human subjects approval was obtained from both the ethics committee at the Universidad Peruana Cayetano Heredia in Lima, Peru, and the Committee on Human Research at University of California, San Francisco.

\section{Analysis}

The interviews were analysed by three investigators in both English and Spanish through a process of thematic coding based on template analysis (Crabtree \& Miller, 1999). One investigator conducted all of the interviews and initially read all of the transcripts, focusing on particular paragraphs of interest for close analysis to create a coding scheme. Both these emergent codes and other codes used in the authors' previous work and thought to be of potential interest in this study composed the code book, which was modified throughout the analysis, adding new codes that emerged. Using the initial code 
book, the investigators each coded the same three transcripts. Perceived limitations and needed clarifications were discussed among the coders to generate definitions of each of the codes, which were then employed moving forward. Each coder coded his or her own batch of three to four transcripts, and the primary author reviewed all coded transcripts for consistency of code definition. Once all of the transcripts were coded, important themes were disaggregated and analysed in depth. The qualitative program ATLAS.ti was used to organise the coded text and share the developing analysis among investigators.

\section{Results}

The study participants had a median age of 29 (range 18-41). Four worked primarily in hairdressing or cosmetology, one had her own salon where she did hairdressing and sex work, three reported primarily working in sex work, two worked in party planning, one worked in a store, one was maintained by her partner and occasionally worked as an assistant in a salon, and three had no regular employment. Nine lived with immediate family, three lived alone, and three lived in rented rooms in a building with other travestis. While not asked explicitly, two reported being HIV positive (Table 1). Each participant was asked what term they use to describe their own identity. These self-identified terms will be used along with the participant's age to identify the source of each quotation in this paper.

\section{Terminology}

When asked what words they use to describe themselves and their gender identity or sexuality, the majority of the participants use the term travesti, while the rest use variously trans, trans or travesti, transformista, and homosexual. When asked to further clarify the distinction between these terms, participants indicate that all biological MSM fall under an umbrella category of being homosexual, while dress and appearance distinguish an individual as gay, transformista, or travesti. Someone who is gay has a male appearance and identity, although he may have some feminine traits or occasionally dress in women's

Table 1. Participant characteristics.

\begin{tabular}{|c|c|c|c|c|c|c|c|}
\hline & Age & Gender identity & Employment & $\begin{array}{l}\text { Living } \\
\text { situation }\end{array}$ & Hormones? & Silicones? & Notes \\
\hline 1 & 28 & Travesti & Sex work & Family & No & No & \\
\hline 2 & 40 & Travesti & Hairdresser & Family & No & No & \\
\hline 3 & 40 & Trans & Hairdresser & Family & No & Yes & \\
\hline 4 & 18 & Trans & Salesperson & Alone & Yes & No & \\
\hline 5 & 41 & Homosexual & Hairdresser & Family & No & No & \\
\hline 6 & 24 & Travesti & $\begin{array}{l}\text { Supported by partner, sometimes } \\
\text { hairdressing }\end{array}$ & Rented room & Yes & Yes & \\
\hline 7 & 37 & Travesti & Sex work & Rented room & Yes & Yes & $\mathrm{HIV+}$ \\
\hline 8 & 24 & Travesti & Sex work & Rented room & No & Yes & \\
\hline 9 & 28 & Transformista & Party planner & Family & Yes & Yes & \\
\hline 10 & 29 & Transformista & Party planner & Family & No & No & \\
\hline 11 & 25 & Trans & Cosmetolgist & Family & Yes & Yes & \\
\hline 12 & 40 & Travesti & Hairdresser and sex work & Alone & No & Yes & \\
\hline 13 & 29 & Trans & Odd jobs & Family & Yes & Yes & HIV+ \\
\hline 14 & 35 & Trans & Unemployed & Alone & Yes & No & \\
\hline 15 & 28 & Travesti & Unemployed & Family & No & Yes & \\
\hline
\end{tabular}


clothes. Travestis utilise female dress full time and transformistas go back and forth between masculine and feminine appearances.

Gays, now this is generalizing, are the homosexuals that appear masculine ... and travestis are those that dress like a woman. (travesti, 40)

Thus, identity is defined first by sexual behaviour (a homosexual has sex with men) and second by outward appearance and dress. To dress full time as a woman reflects a desire to be perceived and accepted as a woman in all aspects of life. On the other hand, transformistas often maintain a masculine appearance during the day, in front of their families or for work, and then lead a social life in feminine dress.

Transformista is because, say, during the day I lead a life dressed as a man, but I mostly dress like a woman for the parties, maybe to take a stroll, to go out, that's when I'll dress like a woman, I transform. It's not that I'm dressed like a woman all day long. (transformista, 28)

These distinctions set up a continuum of homosexual identities, with subtle interplays among appearance, sexual behaviour, and self-perceptions that are not captured by the epidemiologic term 'MSM" or the more colloquial 'gay' or 'transvestite'. It should also be noted that none of these terms incorporate the macho men who often have sex with gays, transformistas, and travestis, but do not consider themselves homosexual.

As we will see, the degree of feminine appearance achieved through body modification and dress affects how a travesti individual is received by neighbours and potential sexual partners and feeds back into self-perception and validation as female. Unfortunately, presenting full time as a woman often also has profound negative effects on family relationships and job prospects. Within a binary system of gender, in a machista ${ }^{1}$ society, there is an advantage to maintaining some fluidity between the two worlds.

While the term travest $i$ is universally understood and employed, trans, which has come to serve as the Spanish-language umbrella term in the political discourse, is not. Of those who primarily identified themselves as trans, most formed part of the same community centre, and another was the youngest participant at 18 years old and was active in a different research-supported community centre. One participant, an identified community leader, describes the recent emergence of the term trans as follows:

They used to be called travestis, even now, some of them don't identify themselves as trans, and they are still called travestis .... The trans thing comes from 3 or 4 years ago I believe.

Before it was travesti and it sounded a little offensive to me. (trans, 25)

A group of participants employs some use of the term trans, primarily in reference to the trans population or the trans community, although they do not identify themselves as trans.

\section{Becoming travesti}

Many of the participants' discussions reflect a deeply embedded belief that the sex into which one is born 'should' be congruous with one of two possible gender categories (man or woman) and all sexual desire 'should' be directed across the invisible aisle. Most participants felt that they could never fully locate themselves in one category, so can never fully be women. Rather, they can strive towards feminine appearances 
and relationships: 'I wanted to appear, not to be a woman, because woman is one thing only, I only wanted to physically look like a woman' (travesti, 24).

Most participants recalled having traditionally feminine childhood traits: wanting to dress in women's clothing and makeup, having feminine tendencies or behaviours, or only wanting to play with or be friends with girls. This creates a great deal of distress for participants:

It was a tremendous argument in my head many times I spent my time thinking in my head for hours and hours stretched out on my bed and crying, asking why this happened to me, why if I was born with a masculine identity do I feel more attraction for feminine things and I like boys? (trans, 25)

This participant describes how her socially assigned gender conflicts with her feminine tendencies and sexual preferences. Social norms have taught her that there is something profoundly wrong with stepping outside the boundaries defined at birth by her genitalia.

In the following quote, one participant describes why a travesti can never be a woman:

Being a woman is a very different thing ... we'll never become women, no matter how much I have my sex changed, and if I have a vagina made, I'll never be a woman. We seem to have the shape, even the looks of a woman, but unfortunately we'll never be that, the truth must be admitted. (travesti, 24)

While not stated explicitly, it is likely that female reproduction is 'that' which can never be achieved by this participant and will prevent her from ever being a woman. Not being born a woman, this participant feels that she can only achieve successive approximations, constantly limited by a heteronormative social discourse that fails to recognise an authentic female transgender identity.

\section{Body transformation}

Body transformation through hormone use and silicone injection, while not universal, is a pervasive aspect of the travesti experience. Industrial silicone, called aceite de avion (airplane oil), is injected into the butt, hips, breasts, forehead, and chin to give a more feminine appearance. Silicones are desired to pass as a woman, earn more in sex work, be more attractive to men, and because attractive travestis are more socially accepted.

... Trans friends who I know who don't look as good femininely ... get harassed ... for a trans who still hasn't fixed herself up physically to be more feminine but dresses as a woman, lets her hair grow out or uses makeup but her features still look a little masculine, there is this type of rejection toward them. (trans, 25)

A travesti who wants to be desired and accepted needs a curvy womanly figure. The fastest, cheapest way to achieve a feminine body is through silicone injections.

In order to attract someone else, that's the most important thing in us, because we are aware that we're not women, especially in ourselves, that we weren't born women. Then, how can we make it up? We have nose jobs, silicones. The others get silicones, and then it's like, Oh, I'm going to get them, too! Because I want to look good, because I like myself, I'm proud, I want to meet a man some day along the way. I want to be loved, to be touched, to be liked, not because of my body, but at least to be liked for who I am. (travesti, 37)

For this participant, silicones are necessary for her to be who she is, to 'make up' for not being born a woman. While it is understandable that she wants her appearance to match 
her identity, she struggles to integrate the exterior and the interior, unable to find a category for her true 'normal' female self.

Despite all of this work to change the body, only one participant wants to have bottom surgery to remove her penis and construct a vagina. In fact, many participants mention getting pleasure from her penis, either through masturbation or through insertive sex. Many sex work clients even pay more to be penetrated by a travesti. The participant quoted below discusses both the pleasure she gets from her penis and also her frustration that, in her view, having a vagina still will not make her a woman.

What would be next to be completely identified as a woman? You'll need to be able to get pregnant, to have a family, and that just won't happen .... On the outside I'd like to look like a woman, but I wouldn't have a sex change ... being a woman is the sum of many things, it's the sum of physical, psychological and emotional characteristics, which can't be achieved in practice, because I ... I look at my DNI [national identification card] and I'm still [my male name], and your DNI says masculine sex, and that creates a psychological struggle ... I can't marry, It's frustrating. I can't be called ma'am, that's frustrating, that will result in psychological disaster. (trans, 35)

In this quote it is clear that the socially defined category of 'woman' necessitates female reproduction. In this sense, it is not the vagina that makes a woman, but the ability to have children. Within a society that does not allow any alternative constructions of womanhood, and that will not even recognise travestis as female on official documentation, a travesti can never achieve a fully integrated sense of self and full realisation of her femininity.

\section{Sexual relationships}

Two important mirrors can validate a travesti's femininity. One is a literal mirror - seeing her reflection and feeling that the image reflected matches her feminine self-perception and makes her feel good. The second, often more important, mirror is the male gaze. Many of the participants talk about the first time they 'became travesti' or the first time they dressed as a woman:

Seeing myself dressed as a woman and made up, I'd never used makeup before, having the long hair which I'd never had ... I liked seeing myself like that and I felt really good and I felt like I was more attractive for the masculine sex because they didn't come on to me as a gay, instead they came on to me as a woman, so I liked that. (trans, 25)

Being desired as a woman, instead of as a gay man, is affirming. But there is a deeper meaning in this quote that comes across in many of the interviews: men find it easier to approach a potential partner when that partner is or appears as a woman, thus not undermining his own heterosexual masculinity.

I've had the need to be travesti, in order to get guys ... there are more opportunities for us girls to have a partner ... . If I don't dress well, if I don't put on make-up, I won't be able to get a partner easily ... that's why the other gay guys, they want to become travestis, to be more attractive. (travesti, 37)

This is not to imply that travestis adopt a feminine appearance only to attract men, but rather that the reactions from men gauge a travesti's success in achieving femininity. 
You'll be more attractive to men, you'll get more clients [if you get silicone injections to change your body]. Besides, you will feel more fulfilled. They'll look at you, you'll look prettier, sexier. Men will .... I'll do it because I want to feel good about myself, not for other people. I'll look prettier, I'll feel good about myself, not just for other people. (travesti, 28)

Discussions of sexual relationships also demonstrate the rigidity and strength of heterosexuality normativity, such that it comes to define travesti desire. The participant quoted below reiterates the assumption that every partnership must have a 'man' and a 'woman'.

I don't see anything nice about it [men who openly go out with other men], I don't know who is the man, nor who is the woman. If one person, how can I explain it, has a form, a body, has a feminine appearance, then you can differentiate ... . (travesti, 24)

Within this context of societal and internalised homophobia, some of the participants report that being travesti is more acceptable than being gay.

I get treated better, let's say, I get into better places ... when I get to the discothèque, they open the door for me, I know that as a man since I'm not made up, with my hair like this, they'll look at me like a mariconcita (little queer). (transformista, 28)

This is likely because feminine appearance can at least be understood as female, whereas an effeminate man who is looking to have sex with men does not fit into any culturally legible gender category.

Participants invariably describe their partners as 'real men', 'heterosexual men', or 'machos', distinguishing them from homosexuals, gays, or effeminate men, reflecting another way in which their relationships are structured within a heteronormative standard. Travestis and their partners reproduce exaggerated 'traditional' gender relations: jealousy and violence as a sign of masculinity and masculine desire; forgiveness and submission as a sign of femininity and feminine desire.

When he saw me [after I got silicones], he went crazy on me. He wouldn't let me go out into the street, and well, with him I'm fine, now he doesn't let me go out, I'm holed up in here [laughs] .... . Now he's more attached to me. (travesti, 24)

This participant views her partner's control of her as a reflection of his desire for and attachment to her. His increased jealousy is a sign that she must be doing something right as a woman. In this sense, travesti identity is built in relation to sex partners in an interaction process framed within a machista environment regarding the perceived dynamics of gender roles. Both the travesti and her partner need each other to become what they are.

Participants forgive their partners for many transgressions out of 'love', or 'because I liked him,' returning again and again to violent partners.

Because I loved him, I still felt I loved him, I left with him, and I didn't care about leaving everything behind. I'd suffered so much, so many months and I left with him, despite everything he'd done to me .... He treated me like a woman. He beat me up, he beat me up like a woman. (travesti, 40)

Violence reaffirms the dominant masculinity of the male partner and, therefore, the submissive femininity of the travesti partner. In addition to replicating a heteronormative script, this dynamic also suggests very low self-esteem, a severe lack of potential partners, and a feeling that she does not deserve any better. 


\section{Violence and discrimination}

Violence and discrimination impact most aspects of the travesti experience. Travestis are subjected to harassment, rape, and physical violence in their homes from family and primary partners; in their neighbourhoods from complete strangers; and in the street from clients, police, pimps, and other characters in the social milieu of sex work. The following quote describes a situation where a participant's partner wanted to force her to have sex without a condom:

I'd always behaved like a lady with him ... but when I told him 'No!' he grabbed my hands strongly, and he wanted to force me, I mean like rape. The man came out in me, I started to curse, the macho came out in me, and I threw him back. (travesti, 40)

Attacks like this one are disturbingly commonplace, and the travest $i$ have no recourse. In fact, the city officials who should be offering protection are themselves a threat: 'Even the police patrol, they insult you, the serenazgo (city patrol), the same, they hit you' (travesti, 28).

Many of the participants' families have rejected them based on their sexuality or femininity, throwing them out of the house, threatening to disown them, or resorting to violence.

My mom's words, they hurt more than a blow, didn't they? When someone hits you, the pain is over soon, but the words stay here in your heart and that's it. Now my mom hates me, she doesn't want to see me. That's why I ran away when I was 15. (travesti, 24)

A few participants, fortunately, had found acceptance from their families, which was instrumental in raising their self-esteem: 'My mom mentioned it to my dad and my dad supported me just the same. Their support has helped me so much to find fulfillment as trans' (trans, 25).

Work-related discrimination often prohibits fully adopting a feminine role day and night. Making permanent or visible changes to one's body, even growing one's hair out, explicitly means not being able to work a 'normal' job. A participant who works in party planning fears that no client would hire her if she had a feminine appearance. 'I mean, let's say I get breast implants ... I'll have to leave the job that I'm at. It's good for me as a person; as a worker it's better to be without breasts, dressed like a boy' (transformista, 28). Thus, she hid her long hair under a cap during the day. On the other hand, for those involved in sex work, travestis with a more feminine appearance can earn more money: 'They picked up all the girls with silicones, they didn't pick me up ... you've gotta have at least hips and butt' (travesti, 28).

\section{Discussion}

In Lima, individuals born male but with a female public appearance and identity primarily socially identify as travesti, with more recent adoption of the term trans or transwoman in more activist circles. Travesti identity entails social and sexual roles, which incorporate feminine, masculine, and uniquely travest $i$ attributes. The non-normative travest identity is constructed and validated within a heteronomative and homophobic framework that defines womanhood and relationships.

The travesti participants in this study do not have a frame that allows them to conceptualise a fully interior transgender identity. They are forced to define their femininity based on how it is reflected back to them, in the form of sexual interest and, unfortunately, 
intimate partner violence. Like cis-gendered individuals, travestis are constantly adapting aspects of themselves so that other people will perceive them as they want to be perceived. When these adaptations fail or are met with violence or discrimination, this rejection becomes re-incorporated into the individual's self-perception Butler (2006) argues that the physical markers of sex only become meaningful and powerful as marks of sex in the course of the body's reiterated performance of gender. Violence and discrimination, when enacted against a travest $i$ as a 'woman' is affirming; when enacted against a 'feminine appearing man' it furthers a cycle of low self-esteem and internalised homophobia.

Unfortunately, for the majority of travestis in Lima, there is no socially recognised way to 'become' a woman. There is also no established legal procedure for changing one's name and sex. These individuals face marginalisation, exclusion, rejection, and violence on a daily basis as they strive to find an 'acceptable' femininity. A travesti can be a hairdresser or a sex worker, but cannot be a businesswoman or a mom. She can be a kept mistress, but cannot be a wife. She can get black market silicone implants and perform in a gay discotheque, but cannot get an identification card with her female name and gender. If she attempts to fight back, it is only through a crack in her femininity that allows her 'macho' side to show through. Although travestis seek relationships in which they are loved and valued for who they are, and which reaffirm the gender identity they feel, these relationships are difficult to achieve, and most sexual and romantic relationships are mediated by an economic component (Salazar et al., 2006, 2010). This context forces travestis underground into illicit transactional economies that increase their risk of harm, including an increased risk of HIV.

\section{Implications for HIV prevention}

Transgender women are the population most affected by the HIV epidemic in Peru and Latin America (Baral et al., 2013), the result of additive problems rooted in social exclusion. Travestis, with their feminine identity and appearance, distinguish themselves from gay and bisexual men, and face a unique set of challenges. This study provides useful data to identify the limits and scope of the categories usually used as MSM and transvestite in the region. This population must be disaggregated from MSM in HIV prevention and surveillance efforts in Peru, to support effective programmes and interventions. Travestis face a tremendous amount of discrimination, homophobia, and transphobia, much of which is so pervasive and deeply felt that it is internalised. Every day is a struggle to meet basic needs and avoid violence. Preventing HIV and seeking treatment once infected is far from the top of the hierarchy of needs. Additionally, gender enhancement procedures occur outside the health system in a parallel system embedded into travesti culture, linked to sex work and the expression of female identity (Kulick, 1998; Silva Santisteban et al., 2012). This perpetuates exclusion and decreases access to HIV prevention programmes and information, as well as health care for other needs. Health personnel at clinics who provide HIV testing and treatment need to be sensitive to the specific needs of the travesti population, including using correct names and pronouns, and avoiding discriminatory or discourteous practices.

We have described vulnerability at the individual level contributing to an increased risk to HIV. If the full realisation of feminine identity implies submissiveness in a relationship, it will remain very difficult for travestis to effectively negotiate for condom use. The 
majority of travestis describe having male partners (Silva Santisteban et al., 2012). Therefore, any effective HIV prevention intervention must include the men who have sex with travestis. For this, we need to better understand this elusive and hidden population. Additionally, interventions aimed at behavioural change need to acknowledge that travestis do engage in insertive anal intercourse, both out of economic necessity and for pleasure. There is urgent need for multilevel culturally tailored interventions, addressing broader issues such as the right to health, identity, and housing, among other basic human rights. Overcoming exclusion remains a huge challenge for travestis and HIV prevention has to be framed in this context.

\section{Conclusion}

Hopefully by now it has become clear why we have chosen to employ the term travesti rather than an English equivalent. The term travesti is frequently translated as 'transvestite', although this is not entirely accurate. First, the term 'transvestite' implies dressing in women's clothes only some of the time, whereas travestis have full-time female dress and feminine identification. Second, the travesti identity entails much more than just dress. Travesti identity is defined primarily by full-time adoption of feminine dress by individuals born male who feel a sexual attraction for men and a deep-rooted internal sense of femininity. Travesti also implies a cultural concept; the construction of an identity within a specific heteronormative context, with its attendant discrimination and rejection. Peruvian activists have recently adopted the term mujer trans (trans woman), as an umbrella term that includes travesti, importing a discourse of acceptance and destigmatisiation. At the same time, they attempt to invert the meaning of travesti to do the same, without losing its specific cultural context.

Work is needed to change many contextual aspects of the travesti experience, to increase self-esteem and decrease the pervasive violence, stigma, and discrimination. To accomplish this, public health and human rights workers need to recognise transgender identity as separate from gay and bisexual men, not only to account for unique challenges and risk factors, but also as one important step towards recognising transfemininity as authentic femininity. One very thoughtful trans leader was passionate about helping other travestis come to the realisation that they are not reducible to just their bodies. She discussed the self-objectification that happens among travestis - that they internalise how others define them by their bodies and appearance and neglect to cultivate other aspects of their lives and personalities:

You should build yourself up as a whole product, you won't just be a pair of tight jeans, some long hair or a pair of little boobs, no, sweetie, you must have something in here ... [that] starts with the love one creates here and which needs to be for one's self. You need to find the way, if this door is closed, I'll look for another one to open, if they close this door, I'll get in through the window, we need to move on, always, always ... it's never too late, the question is to stand up on your feet and to start to walk. (trans, 25)

\section{Limitations}

Like most qualitative work, this study does not aim to include a representative sample. This work represents the perceptions and identity constructions of a particular group of 
travestis in Lima. All interviews were conducted in Spanish by a female investigator from the United States, for whom Spanish is a second language. The complicated dynamics of being a foreign investigator, and representing a renowned Peruvian university could have affected participant responses.

\section{Note}

1. Misogynist, privileging traditional masculinity.

\section{Acknowledgements}

We would like to thank all of the study participants and everyone at la Unidad de Salud, Sexualidad y Desarrollo Humano at UPCH who contributed to this work. Special thanks to Carlos Cáceres and Jeffrey Klausner for their support, which made this work possible.

\section{Disclosure statement}

No potential conflict of interest was reported by the authors.

\section{References}

Baral, S. D., Poteat, T., Strömdahl, S., Wirtz, A. L., Guadamuz, T. E., \& Beyrer, C. (2013). Worldwide burden of HIV in transgender women: A systematic review and meta-analysis. The Lancet Infectious Diseases, 13(3), 214-222. doi:10.1016/S1473-3099(12)70315-8

Barreda, V. (1993). Cuando lo femenino está en otra parte. Revista De Antropología Publicar, Año 2 (3), 29-32.

Bockting, W. O., Robinson, B. E., \& Rosser, B. R. S. (1998). Transgender HIV prevention: A qualitative needs assessment. AIDS Care, 10(4), 505-525. doi:10.1080/09540129850124028

Butler, J. (2006). Gender trouble: Feminism and the subversion of identity. New York: Routledge.

Cáceres, C. F. (1996). Male bisexuality in Peru and the prevention of AIDS. In P. Aggleton, \& P. Aggleton (Eds.), Bisexualities and AIDS: International perspectives (pp. 136-147). London: Taylor and Francis.

Cáceres, C. F., Konda, K. A., Salazar, X., Leon, S. R., Klausner, J. D., Lescano, A. G., ... Coates, T. J. (2008). New populations at high risk of HIV/STIs in low-income, urban coastal Peru. AIDS and Behavior, 12(4), 544-551. doi:10.1007/s10461-007-9348-y

Crabtree, B. F., \& Miller, W. L. (1999). Doing qualitative research (2nd ed.). Newbury Park, CA: Sage.

Instituto Nacional de Estadística e Informática. (2014). Perú: Encuesta Demográfica y de Salud Familiar. Retrieved from https://www.inei.gob.pe/media/MenuRecursivo/publicaciones_ digitales/Est/Lib1211/index.html

Kulick, D. (1998). Travesti: Sex, gender, and culture among Brazilian transgendered prostitutes. Chicago, IL: The University of Chicago Press.

Melendez, R. M., \& Pinto, R. (2007). 'It's really a hard life': Love, gender and HIV risk among maleto-female transgender persons. Culture, Health \& Sexuality, 9(3), 233-245. doi:10.1080/ 13691050601065909

Operario, D., Nemoto, T., Iwamoto, M., \& Moore, T. (2011). Unprotected sexual behavior and HIV risk in the context of primary partnerships for transgender women. AIDS and Behavior, 15(3), 674-682. doi:10.1007/s10461-010-9795-8

Reisner, S. L., Mimiaga, M. J., Bland, S., Mayer, K. H., Perkovich, B., \& Safren, S. A. (2009). HIV risk and social networks among male-to-female transgender sex workers in Boston, Massachusetts. Journal of the Association of Nurses in AIDS Care, 20(5), 373-386. doi:10.1016/j.jana.2009.06.003 
Salazar, X. (2005). Resultados de los Grupos Focales con Trabajadores Sexuales Travestis Sobre el Trabajo Sexual y los Clientes.

Salazar, X., Cáceres, C., Maiorana, A., Rosasco, A. M., Kegeles, S., Coates, T., \& NIMH Collaborative HIV/STI Prevention Trial Group. (2006). Influencia del contexto sociocultural en la percepción del riesgo y la negociación de protección en hombres homosexuales pobres de la costa peruana [Influence of socio-cultural context on risk perception and negotiation of protection among poor homosexual males on the Peruvian coast]. Cadernos De Saúde Pública/Ministério Da Saúde, Fundação Oswaldo Cruz, Escola Nacional De Saúde Pública, 22(10), 2097-2104.

Salazar, X., \& Villayzán, J. (2009). Lineaminetos para el trabajo multisectorial en población trans, derechos humanos, trabajo sexual y VIH/SIDA. Lima: IESSDEH, REDLACTRANS, UNFPA.

Salazar, X., Villayzán, J., Silva Santisteban, A., \& Cáceres, C. (2010). Las personas trans y la epidemia del VIH/SIDA en el Perú: Aspectos sociales y epidemiológicos. Lima: IEESSDEH, UPCH, UNOSIDA, AMFAR.

Sevelius, J. M. (2013). Gender affirmation: A framework for conceptualizing risk behavior among transgender women of color. Sex Roles, 68(11-12), 675-689. doi:10.1007/s11199-012-0216-5

Silva Santisteban, A., Raymond, H. F., Salazar, X., Villayzán, J., Leon, S., McFarland, W., \& Cáceres, C. F. (2012). Understanding the HIV/AIDS epidemic in transgender women of Lima, Peru: Results from a sero-epidemiologic study using respondent driven sampling. AIDS and Behavior, 16(4), 872-881. doi:10.1007/s10461-011-0053-5

Vieria Garcia, M. R. (2008). Care of the body among low-income travestis. Sexualidades, 2, 1-15. 